Article

\title{
Significance of Ubiad1 for Epidermal Keratinocytes Involves More Than CoQ10 Synthesis: Implications for Skin Aging
}

\author{
Florian Labarrade (D), Gopinathan Menon, Laura Labourasse, Catherine Gondran, \\ Karine Cucumel * and Nouha Domloge \\ Ashland Specialties France, Global Skin Research Center 655 route du Pin Montard, \\ 06904 Sophia Antipolis, France; flabarrade@ashland.com (F.L.); gmenon@ashland.com (G.M.); \\ llabourasse@ashland.com (L.L.); cgondran@ashland.com (C.G.); Ndomloge@ashland.com (N.D.) \\ * Correspondence: kcucumel@ashland.com; Tel.: +33-492-941-606
}

Received: 27 November 2017; Accepted: 4 January 2018; Published: 9 January 2018

\begin{abstract}
The significance of Coenzyme Q10 (CoQ10) as an anti-oxidant barrier of the skin, as well as a key component in anti-aging strategies for skin care products, has been firmly established. Biosynthesis of CoQ10 in the mitochondria is well known, but there is only limited information on the non-mitochondrial synthesis of CoQ10 in the skin. Recent findings in zebrafish identified that a tumor suppressor, Ubiad1, is also a key enzyme in the non-mitochondrial synthesis of CoQ10. The purpose of this study was to investigate expression of Ubiad1 in human skin, and its implication in the skin's cutaneous response to oxidative stress. We observed Ubiad1 localization in the epidermis, particularly a subcellular localization in the Golgi apparatus. Ubiad1 modulation by a pentapeptide was associated with an observed reduction in ROS/RNS stresses ( $-44 \% /-19 \%$ respectively), lipid peroxidation $(-25 \%)$ and preservation of membrane fluidity under stress conditions. Electron microscopy of keratinocytes revealed a significant degree of stimulation of the Golgi complex, as well as significantly improved mitochondrial morphology. Given the importance of CoQ10 in mitigating the visible signs of skin aging, our findings identify Ubiad1 as an essential component of the defensive barriers of the epidermis.
\end{abstract}

Keywords: skin; Ubiad1; keratinocyte; coenzyme Q10; Golgi apparatus

\section{Introduction}

Human skin is acutely and chronically exposed to natural and anthropogenic stressors such as ultraviolet radiation, pollutants and chemical organic toxicants, all of which induce varying levels of oxidative stress. Oxidative stress is associated with the generation of excessive amounts of superoxide anion, hydrogen peroxide and hydroxyl radicals [1], which causes the skin to exhibit signs of premature aging by imparting a variety of physical and physiological damage. Several types of interdependent barriers; including antioxidants and tumor suppressor proteins exist in the skin to combat the environmental aggression. Epidermal keratinocytes, the first line of defense, possess antioxidant molecules such as vitamin E, coenzyme Q10 (CoQ10) and ascorbate [2]. Chronological aging also causes a decline in the efficiency of endogenous antioxidative mechanisms and repair processes in general [3], as documented by extensive academic and industry research. CoQ10, first isolated in 1957 [4], has 10-fold higher levels in the epidermis than in the dermis [5,6], and is a very effective antioxidant when exogenously applied [6]. Lowered levels of CoQ10 were also observed in skin cells from older donors [6]. The inhibitory effects of CoQ10 on UVB-induced wrinkle formation have also been investigated by Inui and colleagues [7]. Its biosynthesis requires a large panel of enzymes and is still incompletely characterized. The CoQ10 synthesis reactions occurring in 
mitochondria are clearly described but, due to the presence of CoQ10 in many organelles at higher concentration than in the mitochondria [8], other sites of synthesis in animal cells could be suspected. Ubiad1 (also known as Tere1) was cloned in 2001 [9], and is a protein that belongs to the UbiA superfamily of prenyltransferases [10] and participates in the CoQ10 synthesis pathway by catalyzing the transfer of the isoprenyl groups to an aromatic acceptor [11-13]. Ubiad1 was proposed to be involved in the non-mitochondrial CoQ10 synthesis pathway [14]; however, UBIAD1 implication remain controversial as a study in mice has identified this enzyme as responsible for the synthesis of vitamin K2, but not CoQ9 or CoQ10 [15]. Moreover, Ubiad1 was described in the zebrafish as a key non-mitochondrial CoQ10-forming enzyme, located in the Golgi apparatus [16]. In this study, we investigated Ubiad1 expression in human skin, and showed that Ubiad1 may be involved in the production of non-mitochondrial CoQ10. We demonstrated that Ubiad1 in keratinocytes in vitro can be stimulated by a peptide, with subsequent expansion of cellular Golgi and mitochondrial components. Ubiad1 offers protection for the keratinocyte plasma membrane from exogenous oxidative stress and lipid peroxidation, and also help preserve cell membrane mechanical properties. In view of our new results that reflect increased cellular energetic and versatile roles of Ubiad1 as a tumor suppressor [17], antioxidant generator [6], as well as functioning in cholesterol metabolism [18], we propose Ubiad1 as an interesting and novel target to help combat the visible signs of skin aging.

\section{Materials and Methods}

\subsection{Structure of Ubiad1 Inducer Peptide}

The synthetic peptide was patented (US patent 8,440,789; European patent 2150266). The working solution in experiments was $1 \mu \mathrm{M}$.

\subsection{Antibodies}

Primary antibodies used were anti-Ubiad1 (sc-377013, Santa Cruz Biotechnology, Heidelberg, Germany), anti-Giantin (ab24586, Abcam, Cambridge, UK), anti-3-Nitrotyrosine (ab61392, Abcam, Cambridge, UK). Alexa Fluor ${ }^{\circledR}$ coupled secondary antibodies were used (Molecular Probes, Eugene, OR, USA). Alexa Fluor ${ }^{\circledR} 594$ Phalloidin probe were used for F-actin detection (A12381, molecular Probes, Eugene, OR, USA).

\subsection{Detection of ROS}

CellROX Green probe was used for monitoring intracellular ROS (C10444, molecular Probes, Eugene, OR, USA). Keratinocytes were seeded on 8-well Chamber Slide and incubated with $\mathrm{H}_{2} \mathrm{O}_{2}$ or cumene hydroperoxide. After washing twice, a solution of $5 \mu \mathrm{M}$ CellROX Green was prepared in culture media and applied on cells for $30 \mathrm{~min}$ at $37^{\circ} \mathrm{C}$. Stained cells were washed with PBS, fixed for 15 min with a solution of Formal-Fixx 10\% neutral buffered formalin (Shandon Ltd., Runcor, UK).

\subsection{Lipid Peroxidation Monitoring}

C11-BODIPY (581/591) was used for monitoring lipid peroxidation (D3861, Molecular Probes). Keratinocytes were seeded on 8-well Chamber Slide and incubated with cumene hydroperoxide. After washing twice, BODIPY was prepared in culture media and applied on cells at a final concentration of $0.2 \mu \mathrm{M}$ for $30 \mathrm{~min}$ at $37^{\circ} \mathrm{C}$. Cells were incubated for $30 \mathrm{~min}$ at $37^{\circ} \mathrm{C}$. Stained cells were washed with PBS, fixed for 15 min with a solution of Formal-Fixx $10 \%$ Neutral Buffered Formalin

\subsection{Labeling of the Plasma Membrane}

Keratinocytes were seeded on 8-well Chamber Slide and incubated with cumene hydroperoxide. After washing twice, TMA-DPH (trimethylamine-diphenylhexatriene) (43060, Sigma, St. Louis, $\mathrm{MO}, \mathrm{USA}$ ) was prepared at $2 \mu \mathrm{M}$ in culture media and applied on cells for $15 \mathrm{~min}$ at $37^{\circ} \mathrm{C}$. Stained 
cells were washed with PBS, fixed for 15 min with a solution of Formal-Fixx 10\% Neutral Buffered Formalin (Shandon).

\subsection{HPLC Analysis}

Cells were washed three times with PBS and trypsined. Trypsin was neutralized with culture medium and the suspension was centrifuged at $9000 \times g$ at $4{ }^{\circ} \mathrm{C}$ for $10 \mathrm{~min}$. The pellet was washed with distilled water and centrifuged at $9000 \times \mathrm{g}$ at $4{ }^{\circ} \mathrm{C}$ for $10 \mathrm{~min}$ twice. The pellet was dissolved in $700 \mu \mathrm{L}$ of Hexane/IPA mixture (5:2) and underwent three freezing/thawing cycles, sonication (10 s, 130 Watt, $20 \mathrm{KHz}$, Vibra cell 75185 (Bioblock scientific, Illkirch, France) and centrifugation at $9000 \times \mathrm{g}$ at $4{ }^{\circ} \mathrm{C}$ for $10 \mathrm{~min}$. The supernatant was collected and evaporated in Speed-Vac concentrator Jouan RC1010 (Jouan, Winchester, VA, USA) linked to a cold trap Jouan RCT90 (Jouan, Winchester, VA, USA). Coenzyme Q10 analysis was performed with the HPLC Agilent Technologies 1200 series (Agilent Technologies, Santa Clara, CA, USA) equipped with a quaternary pump (G1311A, Agilent Technologies, Santa Clara, CA, USA), a standard auto sampler (G1329A, Agilent Technologies), a thermostated compartment (G1316A, Agilent Technologies) and an analytical column (Nucleodur 100-5 c18 ec, Macherey-Nagel, PA, USA) connected to a computer with Agilent ChemStation for LC 3D Systems software (version B04.03-SP1, Agilent Technologies, Santa Clara, CA, USA) The calibration was made with CoQ10 (C9538, Sigma, St. Louis, MO, USA) dissolved in IsoPropyl alcohol. The mobile phase for CoQ10 elution was made of $100 \%$ methanol (Thermo Fisher Scientific, Runcorn, Cheshire, UK), the flow rate was $1.1 \mathrm{~mL} / \mathrm{min}$. and the absorbance was read at 210 and $269 \mathrm{~nm}$ with a spectrophotometer Diode Array and Multiple Wavelength Detectors (G1315B, Agilent Technologies).

\subsection{RNA Interference}

Ubiad1 siRNA (HSS179099, Invitrogen, Carlsbad, CA, USA) was transfected with lipofectamine RNAiMAX (Invitrogen, Carlsbad, CA, USA). After $48 \mathrm{~h}$, cells were harvested and analyzed by quantitative polymerase chain reaction. As a negative control Stealth RNAi Negative Control Duplex (Invitrogen) with medium GC content was used as recommended by the manufacturer.

\subsection{Cell Culture}

Normal human epithelial keratinocytes were isolated from skin obtained from plastic surgery of healthy females who had given written informed consent. Keratinocytes were cultured in keratinocyte serum free medium, with provided human recombinant epidermal growth factor and bovine pituitary extract (Gibco, Auckland, New Zealand), and $0.1 \mathrm{mg} / \mathrm{mL}$ Primocin $^{\mathrm{TM}}$ (Invivogen, San Diego, CA, USA). The human immortalized keratinocyte cell line HaCaT, were maintained in Dulbecco's modified Eagle's medium (DMEM, Gibco, Auckland, New Zealand) with 10\% fetal bovine serum (Lonza, Basel, Switzerland) and $0.1 \mathrm{mg} / \mathrm{mL}$ Primocin ${ }^{\mathrm{TM}}$ (Invivogen) at $30{ }^{\circ} \mathrm{C}$ with $5 \% \mathrm{CO}_{2}$.

\subsection{Reverse Transcription-PCR Assays}

Total RNA was extracted using mirVana miRNA isolation kit according to the manufacturer's instructions (Ambion, Austin, TX, USA). Total RNA was reverse transcribed with the high capacity cDNA reverse transcription kit (Applied Biosystems, Branchburg, NJ, USA). Real-time polymerase chain reaction was performed according to the Taqman method, using the TaqMan Universal PCR Master Mix (Applied Biosystems, Carlsbad, CA, USA) with the StepOnePlus Real-time PCR System (Applied Biosystems). Relative expression levels of each target gene were calculated according to the delta-delta-CT method. Probes used for amplification were Hs00203343_m1 for Ubiad1, Hs00153120_m1 for Cyp1a1 and Hs99999901_s1 for 18s mRNA. 


\subsection{Western Blot Analysis}

Keratinocytes were lysed in RIPA buffer (Thermo Scientific, Rockford, IL, USA), containing protease inhibitor cocktail and EDTA (Thermo Scientific). The protein concentration was determined using the BCA Protein Assay Kit (Thermo Scientific) and equal amounts of total protein were loaded on a $4-12 \%$ NuPAGE Bis-Tris Gel (Invitrogen) and transferred onto a nitrocellulose membranes using the iBlot dry blotting system (Invitrogen). Non-specific binding sites were blocked in 5\% milk solution, and membranes were then labelled with appropriate antibodies and developed using the SuperSignal West Femto Maximum Sensitivity Substrate kit (Thermo Scientific).

\subsection{Immunofluorescence}

Methanol-fixed cells were permeabilized in $0.1 \%$ Triton X-100, blocked in $1 \%$ BSA solution. Cells were incubated with primary antibodies diluted in phosphate-buffered saline, followed by incubation with secondary antibodies coupled to Alexa Fluor (Invitrogen). Image acquisition was performed using an Axiovert 200M microscope (Carl Zeiss, Oberkochen, Germany). Photos were captured with an EXI blue camera (Qimaging, Surrey, BC, Canada) coupled to Volocity acquisition software (Perkin Elmer, Waltham, MA, USA). Colocalization of Ubiad1 and Giantin was performed with a statistical approach [19], thus removing the bias of visual interpretation. Pearson correlation coefficient was used as a statistical parameter to quantify the degree of colocalization.

\subsection{Immunohistological Fluorescence}

Human skin samples were obtained from plastic surgery of healthy females who had given written informed consent (Biopredic International, Saint-Grégoire, France). After removal of subcutaneous fat, tissue was used to obtain $6 \mathrm{~mm}$ punch biopsies were taken, fixed in formaldehyde and processed in an automated Shandon Hypercenter XP (Shandon) for paraffin embedding. Sections of $4 \mu \mathrm{m}$ thickness were cut with a microtome (Shandon) and collected on poly-lysine coated glass slides (Menzel Gläser, Braunschweig, Germany) for immunostaining. Heat and pepsin enzymatic antigen retrieval were performed before incubation with Ubiad1 antibody.

\subsection{Electron Microscopy}

Cultured keratinocytes, treated with the peptide at $1 \mu \mathrm{M}$ concentration for $48 \mathrm{~h}$ were fixed in Karnovsky's solution (Emsdiasum, Hatfield, PA, USA) for $1 \mathrm{~h}$ at room temperature, and left for $12 \mathrm{~h}$ at $4{ }^{\circ} \mathrm{C}$. Cells were then carefully scrapped off the petri dish, pelleted with a brief centrifugation, and washed with $0.1 \mathrm{M}$ sodium cacodylate buffer. Pellets were routinely osmicated, dehydrated in a graded series of ethanol, and infiltrated with; and embedded in, a low viscocity epon-epoxy resin. Ultrathin sections of silver-gray interference color were cut and double-stained with uranyl acetate and lead citrate and then examined in a Zeiss 10 transmission electron microscope. Microphotographs were taken with a Gatan digital camera (Gatan, Pleasanton, CA, USA).

\subsection{Statistical Analysis}

All experiments have been repeated, the quantification of the fluorescence was performed by measuring the fluorescent intensity of the staining, which was normalized by cell area. Lipid peroxidation in cells was quantified according to manufacturer guideline with the ratios of the signal from the 590 to 510 channels. Statistical analyses were performed using JMP software (SAS, Cary, NC, USA). Normality testing of the data was performed with the Shapiro-Wilk test. The one-way analysis of variance (ANOVA) was used to determine whether there was any significant difference between the means of two or more independent groups. Difference between two means was performed with Student's $t$-test. A $p$-value $\leq 0.05$ was considered statistically significant $\left(^{*}\right), p$-value $\leq 0.01$ as very significant $\left({ }^{*}\right)$ and $p$-value $\leq 0.005$ as highly significant $(* *)$. 


\section{Results}

\subsection{Ubiad1 Expression and Localization in Human Skin Epidermis}

Immunostaining for Ubiad1 on human skin sections (Figure 1a,b) showed primary localization of the enzyme in the epidermis, although some cells of the dermis were also positive. Within the epidermis, localization of Ubiad1 was strong in the spinous and basal layers (Figure 1a), while it was barely detectable in the stratum granulosum. Interestingly, Ubiad1 showed a particular sub-cellular localization as shown by a strong fluorescence aggregation near the nuclei and many cytoplasmic vesicles, while the plasma membrane was virtually unstained (Figure 1a). Such an asymmetric perinuclear localization strongly suggests that the enzyme is located within cytosolic organelles (Figure 1b).

a

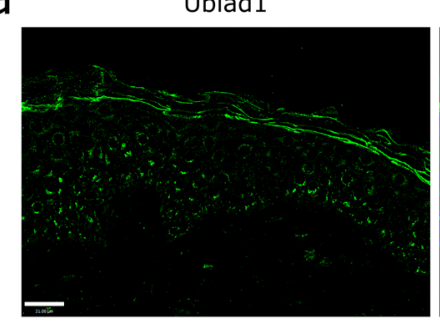

$\mathrm{b}$

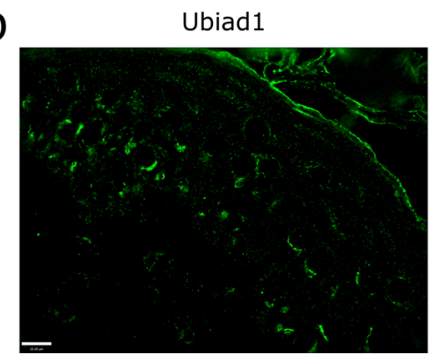

Ubiad1/DAPI

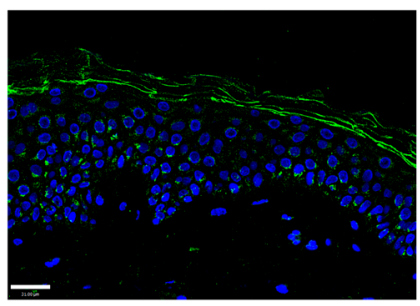

Ubiad1/DAPI

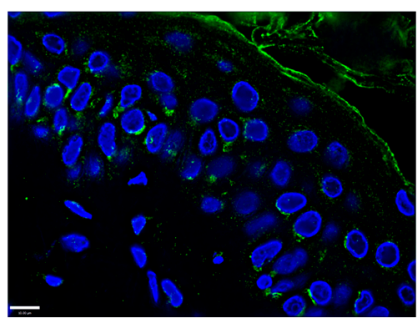

Merged with bright-field

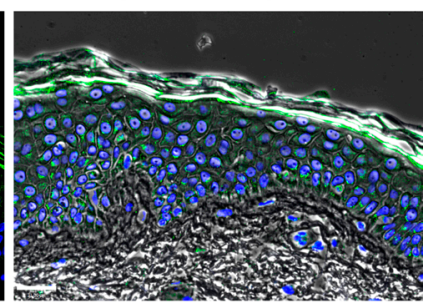

Merged with bright-field

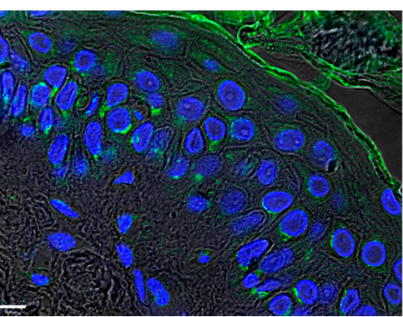

Figure 1. Expression of Ubiad1 in normal skin. (a) Immunodetection of Ubiad1 (green) and DNA stained with $4^{\prime}$,6-diamidino-2-phenylindole (DAPI) (blue), Ubiad1 is positive in the epidermal spinous and basal layers $(\times 20$ objective lens, scale bar $=31 \mu \mathrm{m}) ;(\mathbf{b})$ Immunodetection of Ubiad1 (green) and DNA stained with DAPI (blue), Ubiad1 appears to a tight perinuclear localization, polarly confined (organelle-like) $(\times 63$ objective lens, scale bar $=10 \mu \mathrm{m})$.

\subsection{Ubiad1 Expression and Localization within Keratinocytes In Vitro}

Immunofluorescence staining of cultured cells for endogenous Ubiad1 indicated two distinct distribution patterns: first, a punctate staining, and second, a perinuclear localization reminiscent of the Golgi apparatus (Figure 2). As displayed in the color overlay images, Ubiad1 showed substantial colocalization with Giantin, a protein that is localized in the Golgi complex [20]. Accordingly, the Pearson correlation coefficient was relatively high $(0.79,0.77)$; these observations strongly suggest that Ubiad1 associates with the cis and medial Golgi cisternae. 

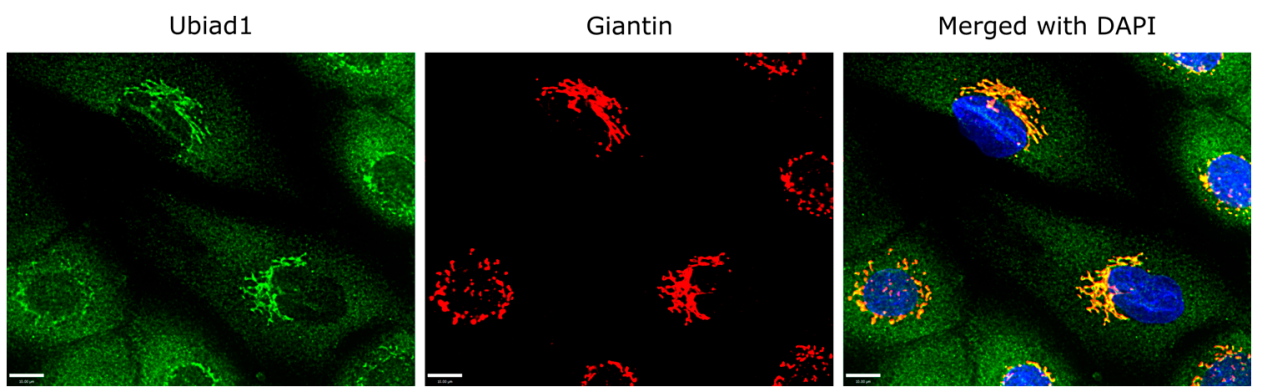

Figure 2. Expression of Ubiad1 in human keratinocytes. Immunodetection of Ubiad1 (green), Giantin (red) and DNA stained with DAPI (blue), protein co-localization (yellow) in cultured human keratinocytes, Pearson's correlation coefficient for cells in middle of the field is relatively high 0.79 and $0.77(\times 63$ objective lens, scale bar $=10 \mu \mathrm{m})$.

\subsection{Ubiad1 Has a Key Protective Role in Keratinocyte Physiology}

A total of $48 \mathrm{~h}$ after transfection, siRNA-induced silencing of Ubiad1 provided a reduced mRNA expression of $92 \%$ (Figure 3a). With the assumption that silencing of Ubiad1 may cause a defect in CoQ10 synthesis, the "weakened" cell lacking in CoQ10 will establish compensative mechanisms to preserve itself from oxidative stress and subsequent lipid peroxidation. We quantified the expression of Cyp1a1, one of the most important detoxification enzymes due to its broad substrate specificity [21]. We also observed that the expression of the CyP1a1 gene is higher in Ubiad1-silenced keratinocyte. In addition, our results indicated that Ubiad1 down regulation, by Ubiad1-siRNA markedly promote ROS accumulation in $\mathrm{H}_{2} \mathrm{O}_{2}$-treated keratinocytes compared with control-siRNA transfected cells also exposed to $\mathrm{H}_{2} \mathrm{O}_{2}$ (Figure $3 \mathrm{c}$, d).

To obtain a better understanding about the benefit of Ubiad1-mediated CoQ10 synthesis, we used a synthetic peptide that was designed to increase Ubiad1 expression in keratinocytes. The capacity of the peptide to increase Ubiad1 expression in keratinocytes, was evaluated by quantitative PCR (fold change $=2.019, n=4$ ) and by immunoblotting (Figure 4a). Furthermore, Ubiad1 expression levels is high in keratinocytes at early culture passage and progressively decrease with passage number (Figure $4 a)$, treatment with the synthetic peptide sustained Ubiad 1 expression $(+54 \%$ at passage 1 and $+62 \%$ at passage 3) (Figure $4 a$ ). Consistent with the elevation of Ubiad1 enzyme, treatment with the peptide promoted an elevation of endogenous CoQ10 synthesis in HaCaT keratinocyte cell line (Figure $4 \mathrm{~b}$ ). Transmission electron microscopy of peptide-treated keratinocytes revealed striking differences in cell morphology between control and treated cells (Figure 4c). Peptide treatment was associated with a large scale increase in the mitochondrial and Golgi content of the cells, resulting in an "activated" state of morphology of the keratinocytes. While mitochondria appeared to have an enlarged and interconnected appearance within the cytosol, the Golgi complex became very prominent, both in numbers of clusters and trans-Golgi elements (Figure 4c).

The membrane-soluble cumene hydroperoxide induced a massive ROS accumulation in keratinocytes (Figure 5a), $+151 \%$ compared to control condition. Keratinocytes treated with the peptide were observed to be more resistant to oxidative stress and reduced ROS generation to effects of cumene hydroperoxide (Figure $5 a, b)$. Treatment with the peptide also reduced cumene hydroperoxide-mediated lipid peroxidation in keratinocytes (Figure 6a,b).

ROS interacts with all biological molecules and causes subsequent cellular damages such as lipid peroxidation, protein damage, and membrane destruction. Keratinocyte membrane permeability was monitored with TMA-DPH (trimethylamine-diphenylhexatriene); a hydrophobic probe exhibiting fluorescence after incorporation into the plasma membrane, cumene hydroperoxide was associated with an observed change in the permeability of the cell membrane (Figure $7 a)(+83 \%$ of fluorescence intensity compared to control condition) (Figure $7 \mathrm{~b}$ ). However, such membrane mechanical properties 
disruption was not observed in keratinocytes treated with the peptide $(+23 \%$ of fluorescence intensity compared to control condition) (Figure 7b).

a

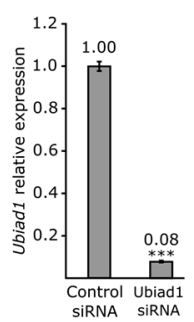

b

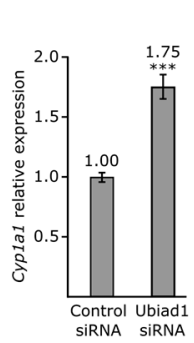

d
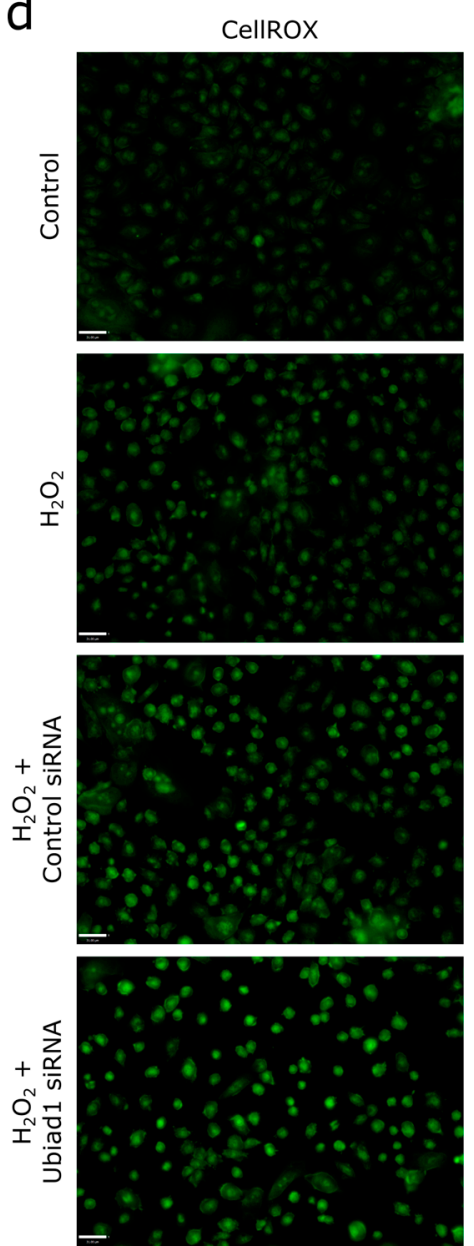

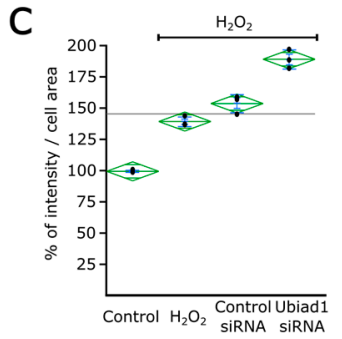

Bright-field
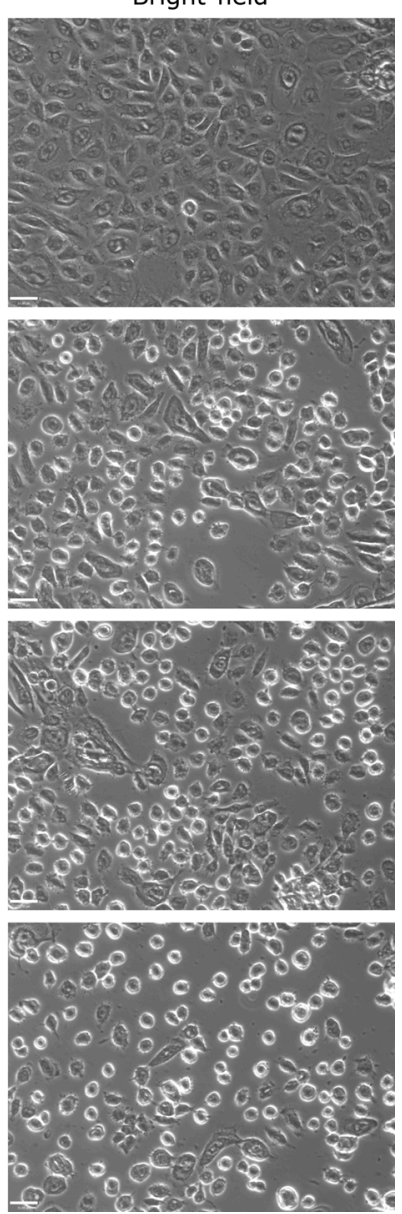

Figure 3. Implications of Ubiad1 in human keratinocyte physiology. (a) Relative quantification of Ubiad1 expression normalized to $18 \mathrm{~S}$ reference gene, $48 \mathrm{~h}$ after Ubiad1 silencing (***: highly significant with Student's $t$ test); (b) Relative quantification of Cyp1a1 expression normalized to $18 S$ reference gene, $48 \mathrm{~h}$ after Ubiad1 silencing (***: highly significant with Student's $t$ test); (c) CellROX quantification graph with One-Way Analysis of Variance, displaying confidence interval means diamonds (green). The line across each diamond represents the group mean. The vertical span of each diamond represents the $95 \%$ confidence interval for each group. Grand sample mean is represented by a horizontal black line; (d) Cellular ROS detection in keratinocyte exposed $30 \mathrm{~min}$ to $2 \mathrm{mM}$ hydrogen peroxide using the CellROX green assay $(\times 20$ objective lens, scale bar $=31 \mu \mathrm{m})$. 

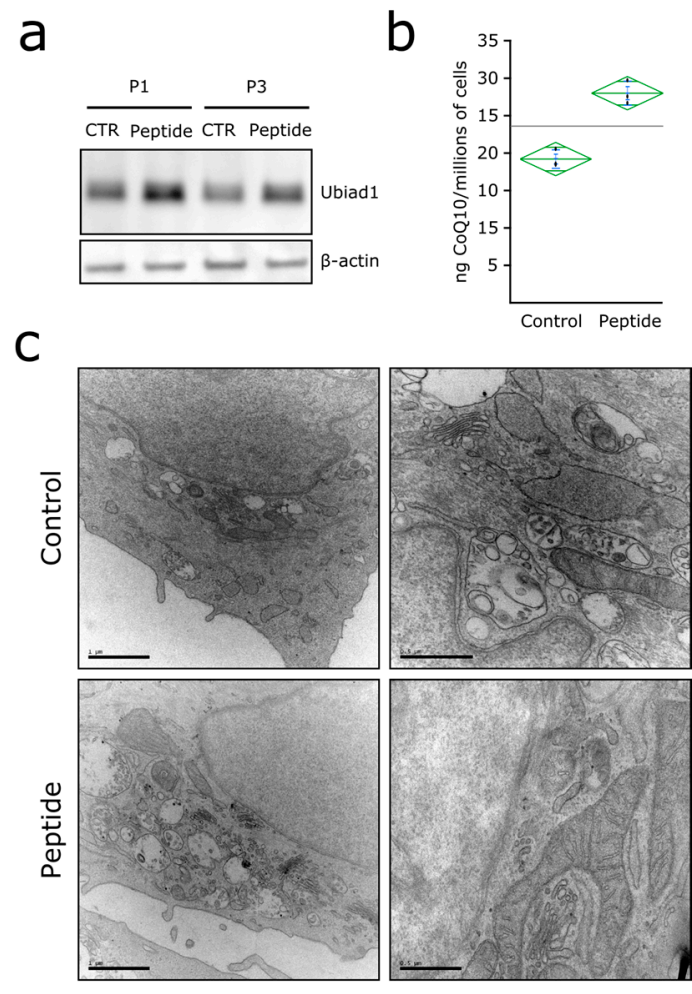

Figure 4. Modulation of Ubiad1 expression and CoQ10 synthesis by synthetic peptide. (a) Immunoblotting of Ubiad1 after treatment with the synthetic peptide $(\mathrm{P} 1=$ culture passage number 1 and $\mathrm{P} 3=$ culture passage number 3); (b) HPLC analyses of endogenous CoQ10 in HaCaT after treatment with the synthetic peptide, quantification graph with One-Way Analysis of Variance, displaying confidence interval means diamonds (green). The line across each diamond represents the group mean. The vertical span of each diamond represents the $95 \%$ confidence interval for each group. Grand sample mean is represented by a horizontal black line; (c) Representative electron microscopy images of an average cell treated with the peptide and double-stained with uranyl acetate and lead citrate (left pictures scale bar $=1 \mu \mathrm{m}$; right pictures scale bar $=0.5 \mu \mathrm{m}$ ).

In addition, Ubiad1 confers protection against SIN-1 peroxynitrite-mediated oxidation, nitrosative stress was evaluated by immunolabeling of 3-nitrotyrosine, a footprint marker of peroxynitrite (ONOO-) and other reactive nitrogen species. Peroxynitrite modification of proteins generates nitrotyrosine, which contributes significantly to protein alterations as an overall part of oxidative damage. Keratinocytes treated with the peptide seem to be more resistant to the nitrosative stress preventing catastrophic protein membrane damage (Figure 8a,b). 
a
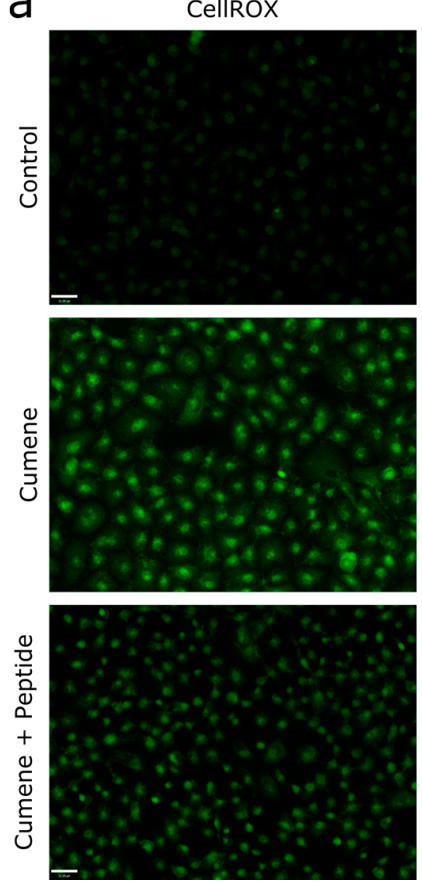

Bright-field
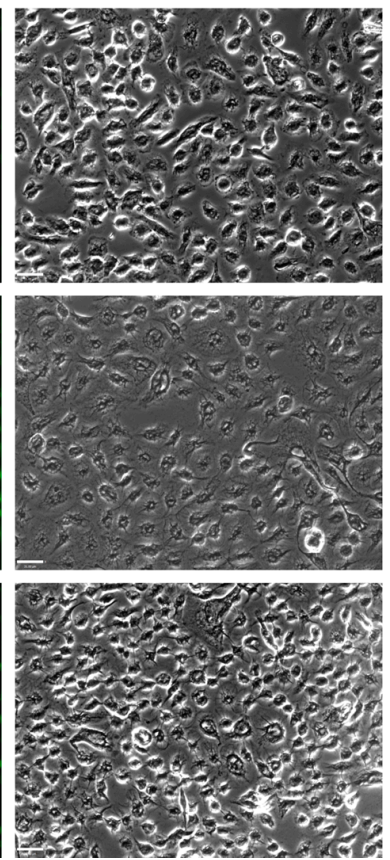

b

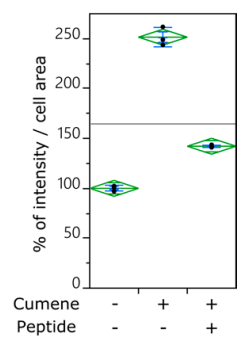

Figure 5. Ubiad1 protect keratinocyte from membrane-soluble cumene hydroperoxide. (a) Cellular Reactive oxygen species (ROS) detection in keratinocyte exposed $1 \mathrm{~h}$ to $200 \mu \mathrm{M}$ cumene hydroperoxide using the CellROX green assay (x20 objective lens, scale bar $=31 \mu \mathrm{m}) ;(\mathbf{b})$ CellROX quantification graph with One-Way Analysis of Variance, displaying confidence interval means diamonds (green). The line across each diamond represents the group mean. The vertical span of each diamond represents the $95 \%$ confidence interval for each group. Grand sample mean is represented by a horizontal black line.

a

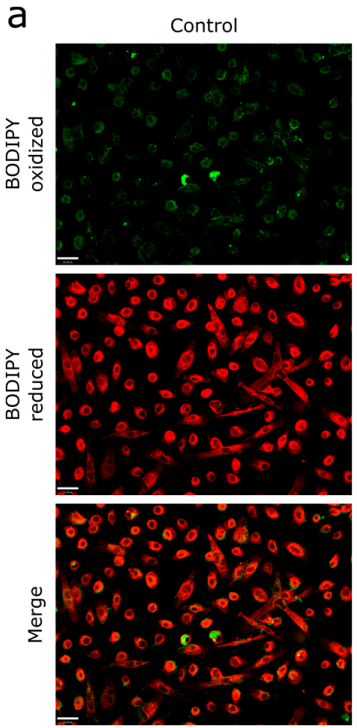

Cumene
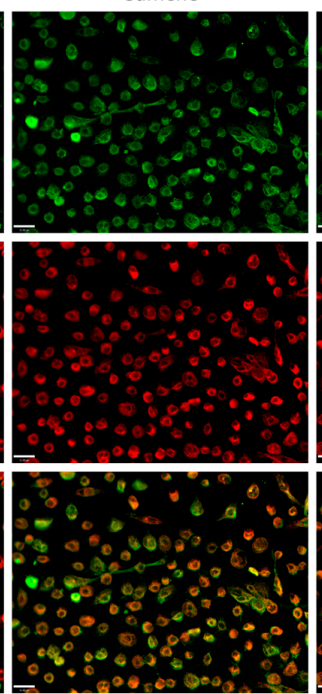

Cumene + Peptide

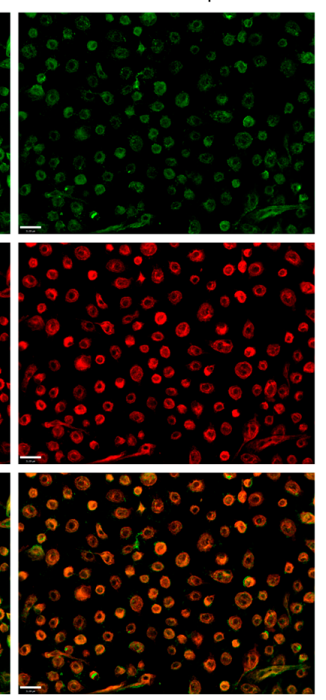

b

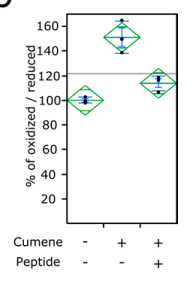

Figure 6. Ubiad1 protect keratinocyte plasma membrane from lipid peroxidation. (a) Lipid peroxidation detection in keratinocyte exposed $1 \mathrm{~h}$ to $200 \mu \mathrm{M}$ cumene hydroperoxide (reduced BODIPY (boron-dipyrromethene) in red; oxidized BODIPY in green) $(\times 20$ objective lens, scale bar $=31 \mu \mathrm{m})$; (b) Lipid peroxidation quantification graph with One-Way Analysis of Variance, displaying confidence interval means diamonds (green). The line across each diamond represents the group mean. The vertical span of each diamond represents the $95 \%$ confidence interval for each group. Grand sample mean is represented by a horizontal black line. 
a
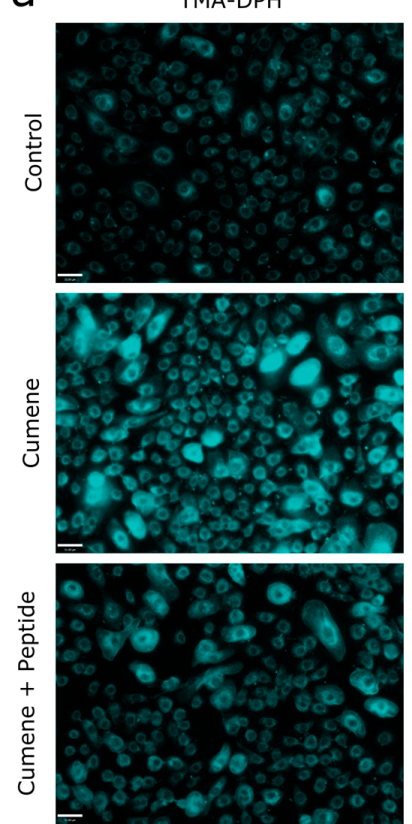

Bright-field
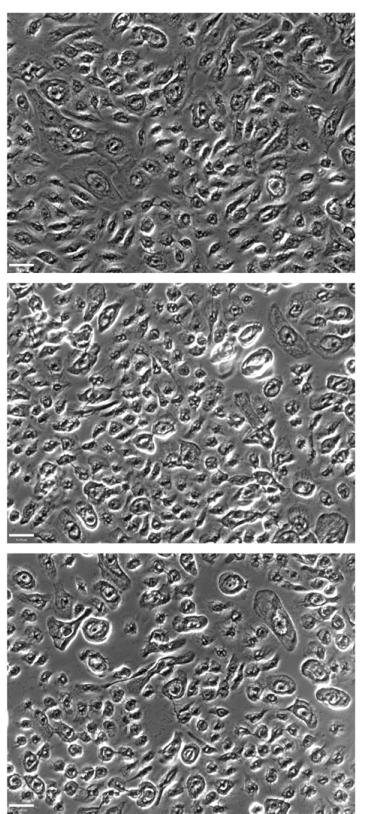

b

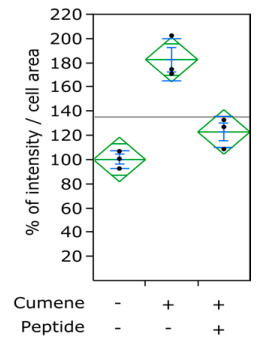

Figure 7. Ubiad1 preserve keratinocyte plasma membrane mechanical properties. (a) Plasma membrane integrity measurement with trimethylamine-diphenylhexatriene (TMA-DPH) probe (blue) in keratinocyte exposed $1 \mathrm{~h}$ to $2 \mathrm{mM}$ cumene hydroperoxide $(\times 20$ objective lens, scale bar $=31 \mu \mathrm{m})$; (b) TMA-DPH quantification graph with One-Way Analysis of Variance, displaying confidence interval means diamonds (green). The line across each diamond represents the group mean. The vertical span of each diamond represents the $95 \%$ confidence interval for each group. Grand sample mean is represented by a horizontal black line.
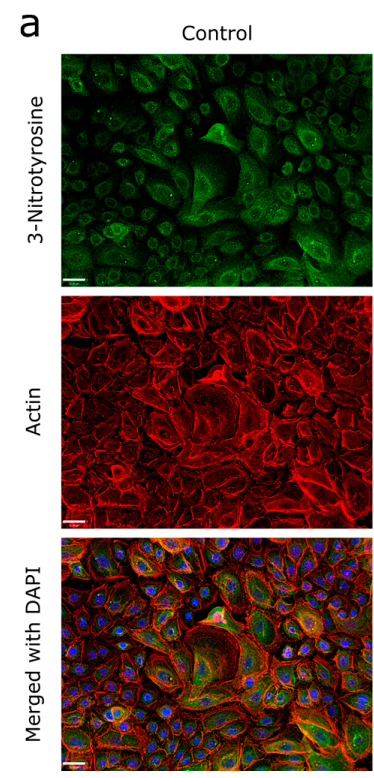

SIN-1
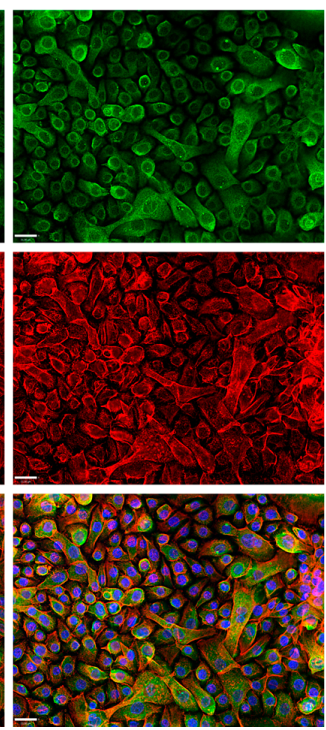

SIN-1 + Peptide
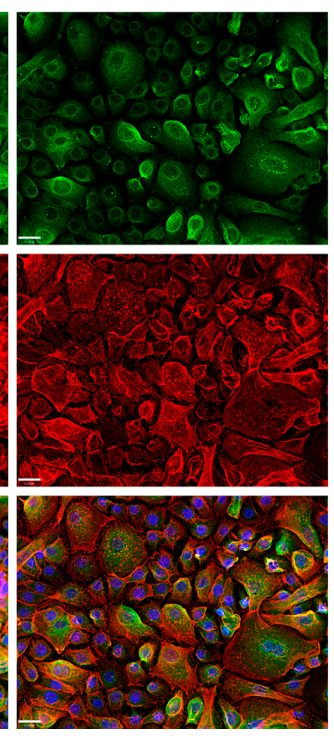

b

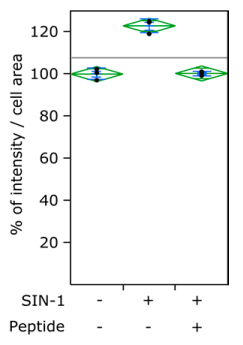

Figure 8. Ubiad1 modulation limits protein nitration by reactive nitric species. (a) Immunodetection of 3-nitrotyrosine (green), F-actin staining with phalloidin (red) and DNA stained with DAPI (blue) in keratinocyte submitted to reactive nitric species stress $(\times 20$ objective lens, scale bar $=31 \mu \mathrm{m})$; (b) 3-nitrotyrosine quantification graph with One-Way Analysis of Variance, displaying confidence interval means diamonds (green). The line across each diamond represents the group mean. The vertical span of each diamond represents the $95 \%$ confidence interval for each group. Grand sample mean is represented by a horizontal black line. 


\section{Discussion}

The importance of CoQ10 in the physiology of cells, tissues and energetics of the organism is well recognized. In the skin, the epidermal compartment has a much higher level of CoQ10 compared to the dermis [2]. It is easy to appreciate the functional significance of high level of a lipophilic antioxidant in the body's first line of defense against oxidant damage. Nevertheless, the subcellular compartments (mitochondria and Golgi) where CoQ10 is synthesized and localized have further implications for epidermal metabolism and barrier functions (both physical and physiological), and also reflect gradients that occur within the epidermis. Keratinocytes of the basal and suprabasal epidermal layers are rich in mitochondria (which generate energy as well as ROS), while the differentiating upper layers are involved in elaborating lipid-enriched lamellar bodies, derived from the Golgi complex. Higher levels of CoQ10 are available in Golgi membrane and plasma membrane than in the mitochondria [8].

Ubiad1, localized to the Golgi complex is now known to be a prenyltransferase that participates in CoQ10 synthesis [16] and is associated with modulation of cellular cholesterol levels [18]. In contrast, it remains unclear whether Ubiad1 is required for CoQ10 synthesis in mice [15]. The latter function is by binding to HMG COA reductase and protecting it from degradation [22], and also by physical interaction with apolipoprotein E [17], making this protein a multifunctional component of the cellular biochemistry, including the first enzyme in Vitamin $\mathrm{K}$ synthesis in humans [11]. UBIAD1 gene expression is also shown to be significantly down regulated in skin during aging [23].

Our results show that treatment with a peptide designed for stimulating Ubiad1-mediated CoQ10 production was associated with a significant improvement in the ultrastructural profile of keratinocyte mitochondria as well as the Golgi complex, which showed a higher level of staining for the Ubiad1 enzyme. Light microscopic imaging of Ubiad1 and Giantin (a Golgin family protein) co-localization defined the Golgi domains, indicating multiple sites of CoQ10 synthesis. A positive effect on the mitochondrial components noted above is beneficial for cellular energetics of keratinocytes. A large body of evidence connects oxidative damage to mitochondrial DNA and proteins with aging changes, especially in keratinocytes and fibroblasts from photoaged skin [24]. Figueiredo and colleagues using a variety of parameters, validated the notion that aging affects the morphology and functional status of mitochondria [25].

As cholesterol is a crucial component of the barrier lipids [26] and Ubiad1 has been recognized as crucial in cellular cholesterol homeostasis [18], the significance of this enzyme in a healthy skin barrier cannot be overemphasized. The recent findings on decreased Ubiad1 gene expression in aging skin [23], when viewed in light of the decreased epidermal sterologenesis and defective skin barrier repair capability of aging skin [27], highlights the potential for the peptide as part of an effective anti-aging strategy for use in skin care applications. Yet another functional benefit may be derived from the tumor suppressor function of Ubiad1 [17], making this strategy a holistic one for anti-aging skin care and skin health.

The human body synthesizes CoQ10 to produce cellular energy in mitochondria and to protect cells from the deleterious effects of free radicals $[28,29]$. The role of oxidative stress in the skin aging process has indeed been well recognized [3,30]. A decrease in the level of CoQ10, the only endogenously produced lipid-soluble antioxidant produced in the cell [28], with ageing has been shown [31]. As discussed previously, ROS may compromise the integrity of cell membranes via peroxidation of membrane lipids [32,33], which impacts mechanical properties of cell membrane.

To assess the consequences of Ubiad1 inhibition on ROS production in Keratinocytes, $\mathrm{H}_{2} \mathrm{O}_{2}$ exposure showed significantly increased in CellROX staining. Ubiad1-silenced condition in presence of $\mathrm{H}_{2} \mathrm{O}_{2}$ promote ROS production at higher level compared to control siRNA (188\%). Differences between $\mathrm{H}_{2} \mathrm{O}_{2}+$ Ubiad1 siRNA is high (35\%) (highly significant $p=0.002$ ) compared with that of $\mathrm{H}_{2} \mathrm{O}_{2}+$ Control siRNA.

When keratinocytes were subjected to an intense level of oxidative stress, it resulted in a perturbation of membrane permeability (Figure $6 a, b$ ), as determined by use of TMA-DPH fluorescence probe. We highlighted the benefits of Ubiad1-mediated CoQ10 synthesis on the ROS production and 
lipids peroxidation in cell membrane. We also shed more light the benefits of Ubiad1 modulation on membrane mechanical properties

When Ubiad1 was down-regulated with an siRNA, we observed expression of a major phase I detoxification metabolism enzyme Cyp1a1 (Figure 2b). Silencing of Ubiad1 was observed to be associated with a higher expression of Cyp1a1, suggesting a compensative mechanism involving inducible enzymes to deal with oxidative stress (Figure 3b). Cytochrome P450 enzymes induction usually enhances detoxification; thus, induction is a protective mechanism. A protective role of Cyp1a1 has been described in the lung, where elevation of Cyp1a1 decreased oxidative stress in this tissue and decreased MDA and 4-HNE, the most prominent end-products of lipid peroxidation [34]. We believe that Cyp1a1 elevation is a compensatory response by keratinocytes to combat lipid peroxidation when Ubiad1 is silenced, and may reveal the importance of Ubiad1 in keratinocyte physiology. Further attention could be focused on CoQ10-dependent antioxidant enzymes such as Cytochrome B5-reductase and $\mathrm{NAD}(\mathrm{P}) \mathrm{H}$ Quinone Dehydrogenase 1. As to nitrosative stress at the plasma membrane, it has been reported that CoQ10 can suppress an excess of reactive nitric species (RNS) and prevents nitrosative stress [35]. ROS and RNS can react with proteins, DNA and lipids, contributing to tissue injury. Moreover, peroxinitrite plays a role in regulation of apoptosis in keratinocytes [36]. Modulation of Ubiad1 attenuates the level of protein nitration, participating in the protection of keratinocytes.

\section{Conclusions}

In conclusion, the present study demonstrates that Ubiad1 is an enzyme expressed in spinous and basal layers of the epidermis; and that its expression reduces during the epidermal differentiation process. Because the effectiveness of endogenous antioxidant systems is diminished during aging, Ubiad1 modulation represents a key aspect for future considerations in the field of skin aging. The skin has developed effective and very specifically-localized anti-oxidative mechanisms; Ubiad1 modulation confers protective benefits against ROS and RNS damage, lipid peroxidation, and plasma membrane fluidity perturbation. Ubiad1 is an interesting target to improve CoQ10 synthesis, thus improve the global physiology of keratinocytes and repel the effects of oxidative stress that can contribute to premature cellular aging. Characterization of Ubiad1 is a first step in the investigation of non-mitochondrial CoQ10 biosynthesis. Further delineation of enzymes able to catalyze other steps in the CoQ10 synthesis, remain to be described in the Golgi apparatus. Personal care industries as well as the pharma sector have long been working on developing effective treatments and ingredients in this area, including naturally derived and synthetic molecules. Small peptides that signal the cells and/or preserve innate biological activity have been part of such efforts. Here we show the effects of one such peptide that has positive effects on the CoQ10 synthesis in vitro. To sum up, since the effectiveness of endogenous antioxidant system is diminished during aging, Ubiad1 modulation represents a key strategy to combat the visible signs of skin aging.

\section{Patents}

The patents annotated in this section are relevant to the article: US patent 8,440,789; European patent 2150266.

Acknowledgments: The authors wish to thank Jason E. Yearout for reading the manuscript and for the English language review.

Author Contributions: Florian Labarrade, and Catherine Gondran conceived and designed the experiments; Florian Labarrade, Gopinathan Menon, and Laura Labourasse performed the experiments; Florian Labarrade, Gopinathan Menon and Catherine Gondran analyzed the data; Florian Labarrade, and Gopinathan Menon wrote the paper, Catherine Gondran revising it critically. Karine Cucumel and Nouha Domloge supervised the study. All authors read and approved the final manuscript.

Conflicts of Interest: The Ubiad1 inducer peptide is patented by Ashland Inc. The authors of this publication are employees of Ashland Inc. 


\section{References}

1. Halliwell, B.; Whiteman, M. Measuring reactive species and oxidative damage in vivo and in cell culture: How should you do it and what do the results mean? Br. J. Pharmacol. 2004, 142, 231-255. [CrossRef] [PubMed]

2. Shindo, Y.; Witt, E.; Han, D.; Epstein, W.; Packer, L. Enzymic and non-enzymic antioxidants in epidermis and dermis of human skin. J. Investig. Dermatol. 1994, 102, 122-124. [CrossRef] [PubMed]

3. Rinnerthaler, M.; Bischof, J.; Streubel, M.K.; Trost, A.; Richter, K. Oxidative stress in aging human skin. Biomolecules 2015, 5, 545-589. [CrossRef] [PubMed]

4. Crane, F.L.; Hatefi, Y.; Lester, R.L.; Widmer, C. Isolation of a quinone from beef heart mitochondria. Biochim. Biophys. Acta 1957, 25, 220-221. [CrossRef]

5. Ernster, L.; Dallner, G. Biochemical, physiological and medical aspects of ubiquinone function. Biochim. Biophys. Acta 1995, 1271, 195-204. [CrossRef]

6. Hoppe, U.; Bergemann, J.; Diembeck, W.; Ennen, J.; Gohla, S.; Harris, I.; Jacob, J.; Kielholz, J.; Mei, W.; Pollet, D.; et al. Coenzyme Q10, a cutaneous antioxidant and energizer. Biofactors 1999, 9, 371-378. [CrossRef] [PubMed]

7. Inui, M.; Ooe, M.; Fujii, K.; Matsunaka, H.; Yoshida, M.; Ichihashi, M. Mechanisms of inhibitory effects of CoQ10 on UVB-induced wrinkle formation in vitro and in vivo. Biofactors 2008, 32, 237-243. [CrossRef] [PubMed]

8. Crane, F.L. Biochemical Functions of Coenzyme Q10. J. Am. Coll. Nutr. 2001, 20, 591-598. [CrossRef] [PubMed]

9. McGarvey, T.W.; Nguyen, T.; Tomaszewski, J.E.; Monson, F.C.; Malkowicz, S.B. Isolation and characterization of the TERE1 gene, a gene down-regulated in transitional cell carcinoma of the bladder. Oncogene 2001, 20, 1042-1051. [CrossRef] [PubMed]

10. Heide, L. Prenyl transfer to aromatic substrates: Genetics and enzymology. Curr. Opin. Chem. Biol. 2009, 13, 171-179. [CrossRef] [PubMed]

11. Nakagawa, K.; Hirota, Y.; Sawada, N.; Yuge, N.; Watanabe, M.; Uchino, Y.; Okuda, N.; Shimomura, Y.; Suhara, Y.; Okano, T. Identification of UBIAD1 as a novel human menaquinone-4 biosynthetic enzyme. Nature 2010, 468, 117-121. [CrossRef] [PubMed]

12. Bonitz, T.; Alva, V.; Saleh, O.; Lupas, A.N.; Heide, L. Evolutionary relationships of microbial aromatic prenyltransferases. PLoS ONE 2011, 6, e27336. [CrossRef] [PubMed]

13. Hirota, Y.; Nakagawa, K.; Sawada, N.; Okuda, N.; Suhara, Y.; Uchino, Y.; Kimoto, T.; Funahashi, N.; Kamao, M.; Tsugawa, N.; et al. Functional characterization of the vitamin K biosynthetic enzyme UBIAD1. PLoS ONE 2015, 10, e0125737. [CrossRef] [PubMed]

14. Mugoni, V.; Medana, C.; Santoro, M.M. 13C-isotope-based protocol for prenyl lipid metabolic analysis in zebrafish embryos. Nat. Protoc. 2013, 8, 2337-2347. [CrossRef] [PubMed]

15. Nakagawa, K.; Sawada, N.; Hirota, Y.; Uchino, Y.; Suhara, Y.; Hasegawa, T.; Amizuka, N.; Okamoto, T.; Tsugawa, N.; Kamao, M.; et al. Vitamin K2 biosynthetic enzyme, UBIAD1 is essential for embryonic development of mice. PLoS ONE 2014, 9, e104078. [CrossRef] [PubMed]

16. Mugoni, V.; Postel, R.; Catanzaro, V.; De Luca, E.; Turco, E.; Digilio, G.; Silengo, L.; Murphy, M.P.; Medana, C.; Stainier, D.Y.; et al. Ubiad1 is an antioxidant enzyme that regulates eNOS activity by CoQ10 synthesis. Cell 2013, 152, 504-518. [CrossRef] [PubMed]

17. Fredericks, W.J.; McGarvey, T.; Wang, H.; Lal, P.; Puthiyaveettil, R.; Tomaszewski, J.; Sepulveda, J.; Labelle, E.; Weiss, J.S.; Nickerson, M.L.; et al. The bladder tumor suppressor protein TERE1 (UBIAD1) modulates cell cholesterol: Implications for tumor progression. DNA Cell. Biol. 2011, 30, 851-864. [CrossRef] [PubMed]

18. Nickerson, M.L.; Bosley, A.D.; Weiss, J.S.; Kostiha, B.N.; Hirota, Y.; Brandt, W.; Esposito, D.; Kinoshita, S.; Wessjohann, L.; Morham, S.G.; et al. The UBIAD1 prenyltransferase links menaquinone-4 synthesis to cholesterol metabolic enzymes. Hum. Mutat. 2013, 34, 317-329. [CrossRef] [PubMed]

19. Costes, S.V.; Daelemans, D.; Cho, E.H.; Dobbin, Z.; Pavlakis, G.; Lockett, S. Automatic and quantitative measurement of protein-protein colocalization in live cells. Biophys. J. 2004, 86, 3993-4003. [CrossRef] [PubMed]

20. Linstedt, A.D.; Hauri, H.P. Giantin, a novel conserved Golgi membrane protein containing a cytoplasmic domain of at least $350 \mathrm{kDa}$. Mol. Biol. Cell 1993, 4, 679-693. [CrossRef] [PubMed] 
21. Ito, S.; Chen, C.; Satoh, J.; Yim, S.; Gonzalez, F.J. Dietary phytochemicals regulate whole-body CYP1A1 expression through an arylhydrocarbon receptor nuclear translocator-dependent system in gut. J. Clin. Investig. 2007, 117, 1940-1950. [CrossRef] [PubMed]

22. Schumacher, M.M.; Elsabrouty, R.; Seemann, J.; Jo, Y.; DeBose-Boyd, R.A. The prenyltransferase UBIAD1 is the target of geranylgeraniol in degradation of HMG CoA reductase. eLIFE 2015, 4. [CrossRef] [PubMed]

23. Glass, D.; Viñuela, A.; Davies, M.N.; Ramasamy, A.; Parts, L.; Knowles, D.; Brown, A.A.; Hedman, A.K.; Small, K.S.; Buil, A.; et al. Gene expression changes with age in skin, adipose tissue, blood and brain. Genome Biol. 2013, 14, R75. [CrossRef] [PubMed]

24. Menon, G.K.; DalFarra, C.; Botto, J.M.; Domloge, N. Mitochondria: A new focus as an anti-aging target in skin care. J. Cosmet. Dermatol. 2010, 9, 122-131. [CrossRef] [PubMed]

25. Figueiredo, P.A.; Powers, S.K.; Ferreira, R.M.; Appell, H.J.; Duarte, J.A. Aging impairs skeletal muscle mitochondrial bioenergetic function. J. Gerontol. A Biol. Sci. Med. Sci. 2009, 64, 21-33. [CrossRef] [PubMed]

26. Elias, P.M.; Feingold, K.R.; Fartasch, M. The Epidermal lamelar body as a multifunctional secretory organelle. In Skin Barrier; Elias, P.M., Feingold, K.R., Eds.; Taylor \& Francis Group: New York, NY, USA, 2006; pp. 261-272, ISBN 978-0-8493-6129-6.

27. Ghadially, R.; Brown, B.E.; Hanley, K.; Reed, J.T.; Feingold, K.R.; Elias, P.M. Decreased epidermal lipid synthesis accounts for altered barrier function in aged mice. J. Investig. Dermatol. 1996, 106, 1064-1069. [CrossRef] [PubMed]

28. Bentinger, M.; Tekle, M.; Dallner, G. Coenzyme Q-biosynthesis and functions. Biochem. Biophys. Res. Commun. 2010, 396, 74-79. [CrossRef] [PubMed]

29. Schniertshauer, D.; Müller, S.; Mayr, T.; Sonntag, T.; Gebhard, D.; Bergemann, J. Accelerated Regeneration of ATP Level after Irradiation in Human Skin Fibroblasts by Coenzyme Q10. Photochem. Photobiol. 2016, 92, 488-494. [CrossRef] [PubMed]

30. Kammeyer, A.; Luiten, R.M. Oxidation events and skin aging. Ageing Res. Rev. 2015, 21, 16-29. [CrossRef] [PubMed]

31. Littarru, G.P.; Langsjoen, P. Coenzyme Q10 and statins: Biochemical and clinical implications. Mitochondrion 2007, 7, S168-S174. [CrossRef] [PubMed]

32. Wong-Ekkabut, J.; Xu, Z.; Triampo, W.; Tang, I.M.; Tieleman, D.P.; Monticelli, L. Effect of lipid peroxidation on the properties of lipid bilayers: A molecular dynamics study. Biophys. J. 2007, 93, 4225-4236. [CrossRef] [PubMed]

33. Jovanović, Z. Effects of Oxidative Stress on the Electrophysiological Function of Neuronal Membranes. In Oxidative Stress and Diseases; Lushchak, V.I., Gospodaryo, D.V., Eds.; InTech Europe: Rijeka, Croatia, 2012; pp. 337-358, ISBN 978-953-51-0552-7. [CrossRef]

34. Lingappan, K.; Jiang, W.; Wang, L.; Wang, G.; Couroucli, X.I.; Shivanna, B.; Welty, S.E.; Barrios, R.; Khan, M.F.; Nebert, D.W.; et al. Mice deficient in the gene for cytochrome P450 (CYP)1A1 are more susceptible than wild-type to hyperoxic lung injury: Evidence for protective role of CYP1A1 against oxidative stress. Toxicol. Sci. 2014, 141, 68-77. [CrossRef] [PubMed]

35. Schöpfer, F.; Riobó, N.; Carreras, M.C.; Alvarez, B.; Radi, R.; Boveris, A.; Cadenas, E.; Poderoso, J.J. Oxidation of ubiquinol by peroxynitrite: Implications for protection of mitochondria against nitrosative damage. Biochem. J. 2000, 349, 35-42. [CrossRef] [PubMed]

36. Wu, S.; Wang, L.; Jacoby, A.M.; Jasinski, K.; Kubant, R.; Malinski, T. Ultraviolet B light-induced nitric oxide/peroxynitrite imbalance in keratinocytes-Implications for apoptosis and necrosis. Photochem. Photobiol. 2010, 86, 389-396. [CrossRef] [PubMed]

(C) 2018 by the authors. Licensee MDPI, Basel, Switzerland. This article is an open access article distributed under the terms and conditions of the Creative Commons Attribution (CC BY) license (http:/ / creativecommons.org/licenses/by/4.0/). 